\title{
Erratum to: Advanced Imaging Techniques in Clinical Pathology
}

\author{
Francesco M. Sacerdoti, Antonio Giordano, \\ and Carlo Cavaliere
}

(C) Springer Science+Business Media New York 2016

F.M. Sacerdoti et al. (eds.), Advanced Imaging Techniques in Clinical

Pathology, Current Clinical Pathology, DOI 10.1007/978-1-4939-3469-0

DOI 10.1007/978-1-4939-3469-0_14

The Publisher regrets to inform the readers that, the editor name 'Carlo Cavaliere' was not listed among the Book editors, which is now corrected.

The updated original online version for this book can be found at DOI 10.1007/978-1-4939-3469-0

F.M. Sacerdoti $(\bowtie) \cdot$ A. Giordano

Temple University, Philadelphia, PA, USA

e-mail: sacerdoti@e-voluzione.it; giordano@temple.edu

C. Cavaliere

NAPLab - IRCCS SDN, Naples, Italy

e-mail: ccavaliere@sdn-napoli.it 